\title{
Sensing parameters as a function of the chemical structure and thickness of two poly(styrene)-type based composites with carbon black
}

\author{
E. Dehonor-Márquez ${ }^{\beta}$, E. Vigueras-Santiago, S. Hernández-Lopéz* \\ Laboratorio de Investigación y Desarrollo de Materiales Avanzados, Facultad de Química - UAEM \\ Toluca, Edo. Méx., 50120, México. \\ ß Posgrado en Ciencia de Materiales, Facultad de Química, Universidad Autónoma del Estado de México \\ Toluca, Edo. Méx., 50110, México.
}

A. Ramírez-Jiménez

CONACyT / Centro de Graduados e Investigación en Química, Instituto Tecnológico de Tijuana

Tijuana, Baja Calif., 22500, México.

(Received: November 29th, 2016; Accepted: March 13th, 2018)

\begin{abstract}
Sensing parameters of polymer composite layers were studied as a function of the polymer matrix structure and the initial resistance of the composite layers. Composites of Poly(styrene) and 4-Chloro-poly(styrene) at the same volume fraction of carbon black $(8.7 \% \mathrm{~V} / \mathrm{V})$ were prepared by ultrasonic dispersion. Composite layers with different thicknesses and resistances were deposited by spin coating technique on flexible substrates from commercial cellulose acetate foils. Both kind of composite layers with initial resistances of 10,50 and $100 \mathrm{k} \Omega$ were exposed to Acetone, Tetrahydrofuran, Chloroform and Toluene. Results evidenced that selectivity is very dependent on the chemical structure of the polymer matrix and sensitivity to the initial film electrical resistance. PS-based composite series were selective to Tetrahydrofuran whereas that 4CIPS-based composite series were selective to Acetone as expected due to their solubility parameters. For both composite series sensitivity increased for layers with less than $100 \mathrm{k} \Omega$ resistances. For all tested solvents $4 \mathrm{CIPS}$-based composites showed higher sensitivities than PS-based composites. The response times for both series were into the range of 2 to $150 \mathrm{~s}$ and recovery times were in the range of 30 to $2000 \mathrm{~s}$.
\end{abstract}

\section{Introduction}

Carbonaceous conductive polymer composites [1-5] have shown to be potential candidates as sensing materials. Interesting characteristics of those polymer-based composites are their easy preparation, low fabrication costs and sensing ability at room temperature. The response mechanism is described on the basis of percolation theory [6,7]. The response optimization in this type of sensors, requires at first, a high solubility of the vapor in the polymer matrix to achieve sharp signals (coming from partial disconnection of the conductive network). Which is governed by the filler morphology [8-11]; the interaction between the conductive particles and the matrix [12]; the effect of the interphase in the increment of sensitivity, in polymer blend matrixes or in semicrystalline polymers; the type, amount and geometry of the carbonaceous particles [13]. Whereas, the selectivity usually is dominated by molecular size and vapor pressure of solvent, temperature, humidity, etc [14-21]. Polystyrene with carbonaceous fillers has been for much one of the most studied polymers as sensor composites [1-6,10,11]. The effect of morphology on the sensing properties $[10,11]$, as well the processing method sampling have been well studied $[10,11]$; and in other works it has been used in pure form or in blends or copolymers with a wide type of solvents [10,22], carbonaceous fillers [10,11] and sensing conditions $[21,23]$. The results has been diverse and with very potential uses. The main goal in this research is to compare the sensing parameters of polymer composites loaded with the same volume fraction of carbon black (CB) and with different polymer matrix structure. Both of those polymer matrixes are amorphous, Poly(styrene) (PS) and the similar 4-Chloro-poly(styrene) (4CIPS), they were synthetized under the same condition in order to have similar properties as molecular mass. 4CIPS has an electronegative chloride atom in the para- or 4-position into the aromatic ring which generates a dipole moment conveying to the polymer higher polarity [24] as evidenced by its Hildebrand parameter (solubility) [25,26]. Additionally, a new variable has been introduced: the initial electrical resistance of composites layers. Composites layers were obtained by spincoating deposition technique. The initial electrical resistance of the film was controlled by the consecutive depositions of composite material. For each type of polymer composite layers with different initial electrical resistances are prepared, 10,50 and $100 \mathrm{k} \Omega$. Solvent sensing experiments were studied under the same conditions at the progressive sensing of the solvents [27]: Acetone (Ace), Tetrahydrofuran (THF), Chloroform (Chl) and Toluene (Tol). We show that the difference in polarity of the polymer matrices has a significant effect on both the selectivity and sensitivity of detection. For instance, 4CIPS-based composite will have a major selectivity to the acetone than PS-based composite, even both have the same differences with the solubility parameter of the acetone. With solvents of less polarity (THF and Chloroform) maybe there are little differences but respect to Toluene definitively PS-based composites should be more selective than 4CIPS-based composites. 


\section{Materials and Methods}

Carbon Black (CB), Polystyrene (PS) and 4-Chloropolystyrene (4-ClPS)

Conductive carbon black Vulcan XC-72 was kindly donated by Cabot Inc. The particle size is in the range of $32 \mathrm{~nm}$, and conductivity is $10-102 \mathrm{~S} / \mathrm{m}$. All the 4 tested solvents: Toluene (Fisher Chem Alert ACS), Chloroform (JT Baker ACS), Tetrahydrofuran (JT Baker ACS) and Acetone (Fermont ACS) were analytical grade reagent and they were used as received. Styrene and 4-Chloropolystyrene were supplied by Sigma-Aldrich, Corp. and they were surpassed by an Alumina Column for separating the inhibitor prior to polymerization. Benzoyl Peroxide (BPO) at $80 \%$ was also supplied by Sigma-Aldrich, Cor. Graduated polypropylene syringes of $1 \mathrm{~mL}$ capacity were used for inject the solvent volumes. Silver paint from Electron Microscopy was used in electrodes.

\section{Material Preparation}

Polymer matrixes were synthetized in bulk via free radicals polymerization using BPO as initiator; and they were purified and characterized as described by Castro et al. [24]. Their dielectric constants were measured respect to temperature and frequency, showing that 4CIPS had a major dielectric constant that PS (2.77 and 2.60, respectively at $\left.23{ }^{\circ} \mathrm{C}\right)$.

An ultrasonic bath Brand Elma, Model Transsonic TI-H-S, was used for solving the polymers and dispersing the carbon black particles. For preparing $5 \mathrm{~g}$ of each composite, $4.2968 \mathrm{~g}$ of PS or $4.3837 \mathrm{~g}$ of 4CIPS, were dissolved in $175 \mathrm{~mL}$ of THF for $30 \mathrm{~min}$ in an ultrasonic bath at $25^{\circ} \mathrm{C}$. $0.7032 \mathrm{~g}$ or $0.6163 \mathrm{~g}$ of conductive $\mathrm{CB}$ were added to the respective polymer dissolution in small portions over 45 min to allow homogeneous dispersion. Once the total CB was added, the ultrasonic dispersion was kept for $16 \mathrm{~h}$ at 75 $\mathrm{kHz}, 50 \%$ power, keeping a constant temperature $\left(25^{\circ} \mathrm{C}\right)$ during all the process. These solutions were used for the layers deposition.

\section{Sensor preparation}

The layers or sensor elements were obtained by spin coating the composite solutions onto cellulose acetate substrates at $1000 \mathrm{rpm}$ in a home-made spin coating. Substrates with an area of $2 \mathrm{~cm} \times 2.5 \mathrm{~cm}$, were previously washed with a soap dilution, and sonicated in ethanol for $5 \mathrm{~min}$. The conductivity of the samples is reached or adjusted by the superposition of one layer after another (number of layers) of the composite solution, as evidenced in other researches $[11,20,28]$. For preparing our composite layers, it was necessary to make around 7 consecutive depositions for reaching $100 \mathrm{k} \Omega, 15$ depositions to have $50 \mathrm{k} \Omega$ and 22 coatings to get $10 \mathrm{k} \Omega$, leaving between consecutive depositions $2 \mathrm{~min}$ of spinning. They were obtained by triplicate for sensing each solvent. The layers were dried at room temperature for $1 \mathrm{~h}$ into a vacuum desiccator. Silver electrodes at $1.5 \mathrm{~cm}$ of distance were placed with silver conductive paint over the composite film, they were dried in a vacuum desiccator for at least 2 days. The electrical
Table 1. Initial electrical resistance average for each series of polymeric composites. Composites of polystyrene (PS) and 4-chloro polystyrene (4ClPS) at the same volume fraction of carbon black $(8.7 \% \mathrm{~V} / \mathrm{V})$

\begin{tabular}{ccccc}
\hline \multirow{4}{*}{ Series } & \multicolumn{4}{c}{ Polymer Composite } \\
\cline { 2 - 5 } & $\begin{array}{c}\boldsymbol{P S}+\boldsymbol{C B} \\
(\mathrm{k} \Omega)\end{array}$ & $\begin{array}{c}\text { Thickness } \\
(\mathrm{nm})\end{array}$ & $\begin{array}{c}\text { 4ClPS }+\boldsymbol{C B} \\
(\mathrm{k} \Omega)\end{array}$ & $\begin{array}{c}\text { Thickness } \\
(\mathrm{nm})\end{array}$ \\
\cline { 2 - 5 } 1 & $10 \pm 0.80$ & $1200 \pm 200$ & $10 \pm 2.0$ & $810 \pm 80$ \\
2 & $50 \pm 2$ & $760 \pm 130$ & $50 \pm 5.0$ & $670 \pm 50$ \\
3 & $100 \pm 20$ & $310 \pm 130$ & $100 \pm 11$ & $310 \pm 20$ \\
\hline
\end{tabular}

resistance of the film were measured using an ohmmeter ASYC II brand, model 5390. Electrical resistance of the layer was measured using a multimeter STEREN MUL model 600 coupled to a computer. Finally, the respective thicknesses for each series were measured using a profilometer Sloan Dektak IIA. In Table 1 is shown the initial resistances and the average thickness of the three series for both groups of the sensors.

\section{Sensing experiments}

The evaluation of change of electrical resistance to Acetone, Tetrahydrofuran, Chloroform and Toluene vapors was carried out by injecting a set of increased volumes into a sensing chamber via a flow of dry, oil-free air. [27,28]. Between solvent pulses, the resistance left to return to a constant value close or equal to the backward value $R_{i}$ reached at relaxation time or recovery time. Fig. 1a shows the sensing parameters (dashed line defines the vapor absorption and desorption step): $R_{i}$ and $R_{\max }$ denotes the initial and the maxima resistances reached after a solvent
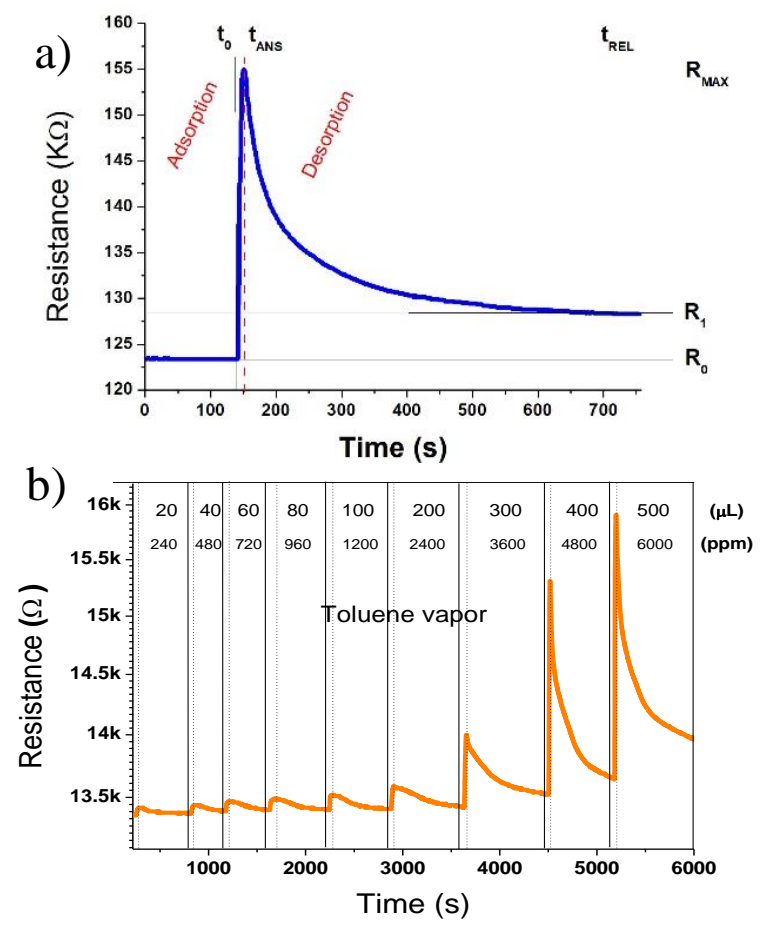

Figure 1. a) Sensing parameters of a dynamic experiment, b) Actual progressive experiment for toluene sensing using a $100 \mathrm{k} \Omega$ PS-based layer composite. We can see a very good correlation between changes in electrical resistance with respect to increased volume of solvent. 
pulse. $R_{\text {res }}$ is the residual value after solvent desorption and it is consider as the new $R_{i}$ for evaluation of the sensing parameters of the next pulse.

Response time are calculate at time which $90 \%$ of $R_{\max }$ are reached and relaxation time was consider the time which $R_{\text {res }}-R_{i}=10 \% R_{i}$. Sensing experiments were done to progressive solvent volumes from 0.01 to $0.5 \mathrm{~mL}$ in increments of $0.02 \mathrm{~mL}$, Fig. 1b. To evaluate reproducibility and the useful lifetime of the composites layers, progressive experiments were performed repeatedly to the same sample. For that, after solvent expositions the sensors were placed into a vacuum desiccator for $16 \mathrm{~h}$ before applying another set of pulses. This was made at least 10 times, after these cycles the layers did not present any damage. Fig. 1b is an example of the real raw signals for a progressive sensing experiment of a PS-based composite layer to toluene. Each peak is produced by an injected pulse and those signals increases in resistivity as the solvent volume does.

\section{Results and discussion}

Sensitivity and selectivity.

From Figure 2 it can be appreciate some important differences between PS- and 4CIPS-based composites:

a) The higher sensitivity of 4CIPS-based composites mainly at volumes up than $200 \mu \mathrm{L}$ for any solvent.

b) 4CIPS-based composites has a higher preference for Ace for volumes less than $100 \mu \mathrm{L}$. Whereas PS-based composites has selectivity for THF at all injected volumes.

c) The tendency of the sensitivity for PS-based composite at any solvent practically doesn't change with the volume. Whereas for 4ClPS-based composites the sensitivity to Ace decreases for volumes up than $200 \mathrm{~mL}$, however it gives the possibility to discriminate it from the other solvents.

The preference for the solvents could be explained in terminus of the solubility parameters of solvents in the different polymeric matrices, which are shown in Table 2.

It is worth note that in all series, 4CIPS-based composite layers had higher sensitivities than those PS-based composites. Due to a good affinity towards acetone the signal for 4CIPS reaches an equilibrium almost instantaneously whereas this evolution was more progressive for THF, Chl and Tol. The source of this selectivity can be found in the nature of interactions between analyte and polymer chains of the matrix. Even both groups of composites have the same preference for some solvents, the sensitivity or capacity to detect them is different thanks to the difference in the chemical structure of the polymer matrixes.

A good affinity of the polymer matrix for some solvent renders high solubility of the polymer in that solvents and the solubility parameter approach is useful for predict this affinity. This approach was first developed by Hildebrand [25], for calculating estimates of the enthalpy of mixing for mixtures of liquids. The solubility parameter is defined as the square root of the cohesive energy density, which in turns is

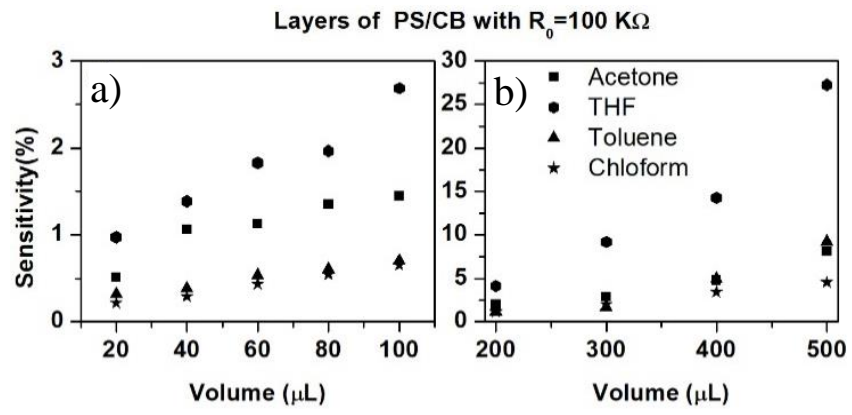

Layers of 4CIPS/CB with $R_{0}=100 \mathrm{~K} \Omega$

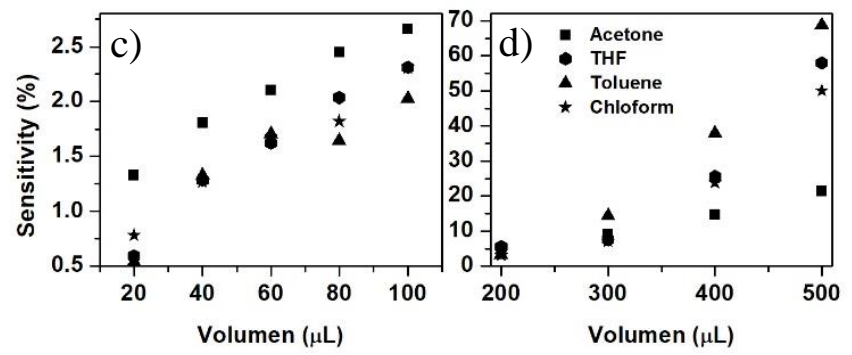

Figure 2. Sensitivity respect to volume of different solvents for $100 \mathrm{k} \Omega$ of initial resistance in a) and b) for PS-based composites, in c) and d) for 4CIPS-based composites.

a measure of the intermolecular attraction forces in a material it approximately equals the heat of vaporization per mol. It has units in (energy/volume $)^{1 / 2}$. For a volatile liquid, cohesive energy density and hence $\delta$ could be determined experimentally but for polymers usually this parameter is calculated by computing tools [26]. The mixing would be favorable as the difference between the solubility parameters $\left(\delta_{1}-\delta_{2}\right)$ of both components tends to zero and there are no hydrogen-bonding interactions in the polymer or the solvent. Although this criterion is not the only one to take into account for ensure a good sensing response, it is an important approach. It is because we are proposing to evaluate how much relevant is a subtle modification on the chemical structure of the polymer matrix in such a way that their solubility parameters be similar or comparable to modify the sensing response of their corresponding conductive composites.

Sensitivity was dependent of initial resistance (thickness) of the layers, see Table 3. For layers with the highest initial resistance of $100 \mathrm{k} \Omega$ are those with the highest sensitivities, they ranging from 0.1 to $30 \%$ whereas the sensitivities of the layers with initial resistance of $10 \mathrm{k} \Omega$ sensitivity range from

Table 2. Solubility parameters of polymers and solvents $[25,26]$.

\begin{tabular}{cccc}
\hline $\begin{array}{c}\text { Polymers and } \\
\text { solvents }\end{array}$ & $\begin{array}{c}\text { Solubility } \\
\text { parameter, } \boldsymbol{\delta} \\
{\left[\left(\mathrm{cal} / \mathrm{cm}^{3}\right)^{1 / 2}\right]}\end{array}$ & $\begin{array}{c}\mid \boldsymbol{\Delta} \boldsymbol{\delta} \text { PS-s } \mid \\
{\left[\left(\mathrm{cal} / \mathrm{cm}^{3}\right)^{1 / 2}\right]}\end{array}$ & $\begin{array}{c}\mid \boldsymbol{\Delta} \boldsymbol{\delta} \mathbf{4} \text { CIPS-s } \mid \\
{\left[\left(\mathrm{cal} / \mathrm{cm}^{3}\right)^{1 / 2}\right]}\end{array}$ \\
\hline PS & 9.2 & & \\
4-ClPS & 10.6 & & 1.7 \\
Tol & 8.9 & 0.3 & 1.3 \\
Chl & 9.3 & 0.1 & 1.3 \\
THF & 9.3 & 0.1 & 0.7 \\
Ace & 9.9 & 0.7 & \\
\hline
\end{tabular}


0.1 to $5 \%$ only. It could be explained in terms of the thickness of the layers: an increment of the deposited layers by spin coating technique implies an increment of the thickness too $[19,25,29]$, Table 1 . It is clear that the resistance decreases as the number of deposition coatings increases, and it is possible to control the resistance to a value range. A bigger carbon network disconnection results in a greater electrical response and it happens when molecules of solvent have good affinity for the polymer matrix, they penetrate and separate the carbon/carbon junctions. Thus the probability for significant network disconnection and consequently large response, is higher at low filler content, because the number of efficient conducting branches is lower. So there are fewer conduction networks in a thinner layer than in a thicker one, if those both layers were exposed to the same solvent volume causing the same disconnection of conductive networks, the change on the resistivity would much more significant for the layers containing less electrical pathways (thinnest). This results from the well-established percolation theory, which states that polymer composites with filler content close to the percolation threshold give sharper responses to changes of their environment.

Otherwise we could appreciate a great difference in the preference (selectivity) to determined solvent. For PS-based composite layers of $10 \mathrm{k} \Omega$, Table 3 ; it seems not to have a

Table 3. Sensitivity of the PS and 4CIPS-based composites, for initial resistances of 10 and $50 \mathrm{k} \Omega$.

\begin{tabular}{lcccccccccc}
\multicolumn{10}{c}{ Sensitivity (\%) } & $\mathbf{R}_{\mathbf{0}}=\mathbf{1 0} \mathbf{~ k \Omega}$ \\
\hline $\begin{array}{c}\text { Solvent } \\
(\mu \mathrm{L})\end{array}$ & $\mathbf{2 0}$ & $\mathbf{4 0}$ & $\mathbf{6 0}$ & $\mathbf{8 0}$ & $\mathbf{1 0 0}$ & $\mathbf{2 0 0}$ & $\mathbf{3 0 0}$ & $\mathbf{4 0 0}$ & $\mathbf{5 0 0}$ \\
Ace & 0.36 & 0.56 & 0.82 & 0.98 & 1.10 & 1.54 & 2.29 & 3.8 & 4.5 \\
THF & 0.11 & 0.22 & 0.22 & 0.26 & 0.26 & 0.37 & 0.59 & 1.0 & 1.6 \\
Tol & 0.07 & 0.20 & 0.26 & 0.32 & 0.52 & 0.72 & 2.18 & 3.8 & 4.5 \\
Chl & 0.20 & 0.25 & 0.41 & 0.48 & 0.67 & 0.86 & 1.50 & 3.0 & 4.4 \\
\hline \multicolumn{10}{c}{ 4-CIPS-based composite } \\
\hline Ace & 0.46 & 1.2 & 1.4 & 1.6 & 1.7 & 2.3 & 4.5 & 7.3 & 10.1 \\
THF & 0.32 & 0.39 & 0.52 & 0.65 & 0.71 & 1.7 & 2.8 & 4.3 & 12.2 \\
Tol & 0.19 & 0.34 & 0.45 & 0.49 & 0.58 & 0.92 & 1.9 & 4.4 & 6.9 \\
Chl & 0.32 & 0.55 & 0.86 & 1.0 & 1.3 & 2.1 & 3.7 & 4.8 & 8.3 \\
\hline
\end{tabular}

\begin{tabular}{lccccccccc}
\multicolumn{1}{c}{ Sensitivity (\%) } & $\mathbf{R}_{\mathbf{0}}=\mathbf{5 0} \mathbf{~} \boldsymbol{\Omega}$ \\
\hline Ace & 0.47 & 0.80 & 0.94 & 1.1 & 1.2 & 1.5 & 2.5 & 4.8 & 6.0 \\
THF & 0.45 & 0.82 & 1.0 & 1.2 & 1.6 & 2.6 & 4.4 & 8.2 & 11.8 \\
Tol & 0.20 & 0.30 & 0.51 & 0.51 & 0.50 & 0.91 & 1.6 & 2.2 & 4.6 \\
Chl & 0.13 & 0.33 & 0.46 & 0.59 & 0.58 & 0.84 & 1.6 & 2.2 & 3.2 \\
\hline \multicolumn{10}{c}{ 4-ClPS-based composite } \\
\hline Ace & 0.41 & 0.85 & 1.1 & 1.4 & 1.4 & 1.9 & 2.7 & 6.1 & 8.6 \\
THF & 0.16 & 0.41 & 0.53 & 0.83 & 0.97 & 1.6 & 2.2 & 3.8 & 9.1 \\
Tol & 0.19 & 0.38 & 0.38 & 0.57 & 0.58 & 0.96 & 2.1 & 2.1 & 3.4 \\
Chl & 0.28 & 0.43 & 0.43 & 0.71 & 0.71 & 1.1 & 1.7 & 3.3 & 4.7 \\
\hline
\end{tabular}

relationship with the solubility parameters prediction. For volumes smaller than $200 \mu \mathrm{L}$, it is clear that sensitivity is governed by the vapor pressure of the solvents [10,17]. At first the thickest layer responds simply to the presence of the slightly or considerably amount of solvent in the environment, without taking into account the preference. For volumes higher than $200 \mu \mathrm{L}$, there is an important adsorption, recognize and preference most according to the solubility parameters. It is because $\mathrm{Tol}$ and $\mathrm{Chl}$ are equal to Ace in sensitivity at $500 \mu \mathrm{L}$. This tendency changes for more resistive and thicker layers. In this case, PS-based composites of $50 \mathrm{k} \Omega$, Table 3 , they show a bigger sensitivity for THF than for acetone, independent of the injected volume.

Unlike of the previous results, 4ClPS-based composites do not follow the same tendency as PS-based composites. Both 4CIPS-based thicker layers series (10 and $50 \mathrm{k} \Omega$ ), the preference is the same: first Ace and then THF, independent of the injected volume. In case of the thinnest series $(100 \mathrm{k} \Omega$ ), the same tendency is observed from 20 to $100 \mu \mathrm{L}$ of injected solvent. Up to $100 \mu \mathrm{L}$ the sensitivity start to change and THF and Tol get preference. This last effect could be due to that some of the solvent (Tol) is not completely desorbed from the thin layers. Toluene takes longs times to be desorbed as we could show in the recovering time discussion. In order to the layer reach a constant resistivity value before another Tol pulse takes many minutes and never reach the previous resistance value, indicating some disconnected conductive networks and/or a very different configuration of the particles and polymer chains in the composite respective to the previous rearrangements.

\section{Response and recovery times}

In general for both groups and their series, the response time in increscent order was always: Ace $>\mathrm{THF} \sim \mathrm{Chl}>$ Tol, that match very well with decrement of the vapor pressure of the solvents. Acetone is detected very fast in the range from 3 to $8 \mathrm{~s}$, independent of the polymer matrix, resistivity of the layer and of the injected volume. Whereas Tol takes from 10 to $35 \mathrm{~s}$ in being detected, the response time is dependent on the injected volume. In Table 4 is shown as an example, this behavior with the thinnest layers (the most sensitives).

Acetone in both series is detected at the same time independently of the injected volume, for 4CIPS series this time is smaller (5 s in average) than for PS series ( $8 \mathrm{~s}$ in average). For Tol the tendency is different than for Ace and for the other solvents. For PS based-layers, detection of Tol takes in average between 12 and $15 \mathrm{~s}$ at all volumes excepting for $100 \mu \mathrm{L}$, which showed a maxima response time of $35 \mathrm{~s}$. For 4CIPS- based layers, the response time to Tol is dependent on the injected volume, it starts to increase as de volume increases, from 11 to $30 \mathrm{~s}$ until it reaches a maximum of 50s for a volume of $100 \mu \mathrm{L}$ (as for PS-based layers) after this volume the response time decreases building a Gauss's bell. This behavior of Tol is shown for the other two series too, the maximum time is reached at $80 \mu \mathrm{L}$ for 50 and $10 \mathrm{k} \Omega$ series. Maybe those volumes (80 or 
Table 4. Response times for PS and 4CIPS-base composites at $100 \mathrm{k} \Omega$ of initial resistance

\begin{tabular}{lllllllllll}
\multicolumn{8}{c}{ Response time (s) } & $\mathbf{R}_{\mathbf{0}}=\mathbf{1 0 0} \mathbf{~ k \Omega}$ \\
\hline $\begin{array}{l}\text { Solv. } \\
(\mu \mathrm{L})\end{array}$ & $\mathbf{2 0}$ & $\mathbf{4 0}$ & $\mathbf{6 0}$ & $\mathbf{8 0}$ & $\mathbf{1 0 0}$ & $\mathbf{2 0 0}$ & $\mathbf{3 0 0}$ & $\mathbf{4 0 0}$ & $\mathbf{5 0 0}$ \\
Ace & 5.3 & 7.0 & 6.0 & 8.0 & 6.7 & 7.0 & 7.3 & 8.7 & 6.3 \\
THF & 5.2 & 7.7 & 6.7 & 7.7 & 7.0 & 8.8 & 6.7 & 7.7 & 8.8 \\
Tol & 12.0 & 10.3 & 11.3 & 8.0 & 35.0 & 17.7 & 11.3 & 14.8 & 15.2 \\
Chl & 4.3 & 3.7 & 5.3 & 8.3 & 7.3 & 12.2 & 6.8 & 7.7 & 6.7 \\
\hline \multicolumn{10}{c}{} & \multicolumn{10}{c}{ 4CIPS-based composites } & & & \\
\hline Ace & 3.0 & 3.0 & 2.8 & 2.7 & 3.0 & 3.0 & 2.7 & 5.5 & 5.7 \\
THF & 5.0 & 6.3 & 6.8 & 5.8 & 6.0 & 7.3 & 7.8 & 6.8 & 7.7 \\
Tol & 11.0 & 19.5 & 21.7 & 27.8 & 50.2 & 27.8 & 22.7 & 14.7 & 11.8 \\
Chl & 3.3 & 4.5 & 5.8 & 17.3 & 4.7 & 4.7 & 5.7 & 6.7 & 7.7 \\
\hline
\end{tabular}

$100 \mu \mathrm{L}$ ) the composites reach a maximum absorption of that solvent.

With respect to recovering time, in general the decreasing order for returning to a constant resistivity value after a pulse is the same as for response time. Acetone is desorbed much faster than THF, Chl and Tol, independent on the series and injected volume. The range of 10 and $50 \mathrm{k} \Omega$ is around $125 \mathrm{~s}$ for PS-based layers and $90 \mathrm{~s}$ for 4CIPS based composites, both for Acetone. For Tol the times increase until $2500 \mathrm{~s}$ and $2000 \mathrm{~s}$ for the same series, respectively. Again, an example of the tendency for the recovery time for the series of $100 \mathrm{k} \Omega$, is shown in Table 5 .

In general these times are smaller than for the other two series, however for PS-bases composites this time is dependent on the injected volume. As this volume increases the desorption time also increases and it is much significant up to $100 \mu \mathrm{L}$ which is the injected volume at the layers have the highest response time. For 4CIPS is the recovering time has the same behavior as the response time. It increases with the injected volume until a maximum for $100 \mu \mathrm{L}(1600 \mathrm{~s})$ and then it starts to decreases for greatest volumes. This

Table 5. Recovery time for PS and 4CLPS base composites at $100 \mathrm{k} \Omega$ of initial resistance

\begin{tabular}{|c|c|c|c|c|c|c|c|c|c|}
\hline \multicolumn{6}{|c|}{ Desorption time (s) } & \multicolumn{4}{|c|}{$R_{0}=100 \mathrm{k} \Omega$} \\
\hline \multicolumn{10}{|c|}{ PS-based composite } \\
\hline $\begin{array}{l}\text { Solv. } \\
(\mu \mathrm{L})\end{array}$ & 20 & 40 & 60 & 80 & 100 & 200 & 300 & 400 & 500 \\
\hline Ace & 41 & 81.0 & 63 & 98 & 84 & 135 & 99 & 119 & 109 \\
\hline THF & 80 & 78 & 136 & 134 & 184 & 293 & 518 & 397 & 720 \\
\hline Tol & 63 & 101 & 229 & 296 & 634 & 918 & 1052 & 1944 & 1625 \\
\hline Chl & 136 & 192 & 248 & 299 & 382 & 451 & 395 & 589 & 783 \\
\hline \multicolumn{10}{|c|}{ 4CIPS-based composite } \\
\hline Ace & 30 & 37 & 39 & 44 & 50 & 73 & 104 & 240 & 432 \\
\hline THF & 87 & 163 & 148 & 182 & 165 & 658 & 652 & 1793 & \\
\hline Tol & 244 & 601 & 787 & 1239 & 1532 & 1475 & 1336 & 893 & 811 \\
\hline Chl & 29 & 45 & 61 & 64 & 80 & 105 & 235 & 649 & 401 \\
\hline
\end{tabular}

different behavior between recovering time for PS and 4CIPS could be due to greatest affinity of the Tol for the PS matrix, it is interacting stronger and in turns it is more difficult (takes more time) to desorb from the composite at large injected volumes.

\section{Conclusions}

It was clear that the chemical structure is very important in the sensing parameters; in this study two series of composites at the same volume fraction of carbon black and with a little different polymer matrix were submitted at the same sensing studies with the same solvents. Even they were sensitivities to all of the solvents and some tendencies were similar, the magnitude of the evaluated sensing parameters (sensitivity, response time and recovery time) were different for each group/series. These differences in magnitude allow to choose appropriately the composite with the desired characteristics for a particular sensing process. In general it could be concluded from the results that for injected volumes down to $100 \mu \mathrm{L}$, it could be observed a coherent tendency in the layers sensors: more resistive layers render a higher sensitivity and a faster response times to the solvent with the nearest solubility parameter to the polymer matrix. Recovery times same to be associated to the capacity of evaporation of the solvent and in some point for the nature of the interaction of it with the composite polymer.

\section{Acknowledgements}

Authors thank to the UAEM for Project No. 1025/2014RIFC; to CONACyT by the fellowship for Master Studies of Ethnice Dehonor Márquez, and to Alejandro Esparza from CCADET-UNAM, for the thickness measurements.

\section{References}

[1]. Y.S. Kim, S.C. Ha, Y. Yang, Y. Jun. Kim, S.M. Cho, H. Yang, Y.T. Kim, Sens. Actuator. B-Chem. 108, 285 (2005).

[2]. M.C. Lonergan, E.J. Severin, B.J. Doleman, S.A. Beaber, R.H. Grubbs, N.S. Lewis, Chem. Mater. 8, 2298 (1996).

[3]. F.K.C. Harun, A.M. Jumadi, N.H. Mahmood, Intl. J. Sci. Eng. Res. 2, 1 (2011).

[4]. A.C. Partridge, M.L. Jansen, W.M. Arnold, Mater. Sci. Eng. C $\underline{12,37(2000) \text {. }}$

[5]. M. Kozlowski, S. Fracowiak, Sens. Actuator. B-Chem. 109, 141 (2005).

[6]. H. Deng, L. Lin, M. Ji, S. Zhang, M. Yang, Q. Fu, Prog. Polym. Sci. 39, 627 (2014).

[7]. A. Carrillo, I.R. Martín-Domínguez, A. Márquez, Sens. Actuator. B-Chem. 113, 477 (2006).

[8]. C. Roman, O. Bodea, N. Prodan, A. Levi, E. Cordos, I. Manoviciu, Sens. Actuator. B-Chem. 25, 710 (1995).

[9]. J.W. Hu, S.G. Chen, M.Q. Zhang, M.W. Li, M.Z. Rong, Mat. Lett. 58, 3606 (2004).

[10]. J.F. Feller, Y. Grohens, Synth. Met. 154, 193 (2005).

[11]. J.F. Feller, H. Guezenoc, H. Bellegou, Y. Grohens, Macromol. Symp. 222, 273 (2005).

[12]. J.R. Li, J. Wang, J.R. Xu, M.Q. Zhang, M.Z. Rong, Q. Zheng, Compos. Sci. Technol. 66, 3126 (2006).

[13]. R. Sanjinés, M.D. Abad, Cr. Vâju, R. Smajda, M. Mionić, A. Magrez, Surf. Coat. Technol. 206, 727 (2011). 
[14]. X.M. Dong, R.W. Fu, M.Q. Zhang, B. Zhang, M.Z. Rong, Carbon 42, 2551 (2004).

[15] L. Quercia, F. Loffredo, M. Bombace I. Nasti, G. Di Francia, Sens. Actuator. B-Chem 111-112, 166 (2005).

[16]. B. Zhang, X. Dong, R. Fu, B. Zhao, M. Zhang, Compos. Sci. Technol. 68, 1357 (2008).

[17]. B.J. Doleman, E.J. Severin, N.S. Lewis, Proc. Natl. Acad. Sci. USA 95, 5442 (1998).

[18]. X.M. Dong., R.W. Fu, M.Q. Zhang, B. Zhang, J.R. Li, M.Z. Rong, Polym. Bull. 50, 99 (2003).

[19]. S.G. Chen, X.L. Hu, J. Hu, M.Q. Zhang, M.Z. Rong, Q. Zheng, Sens. Actuator. B-Chem. 119, 110 (2006).

[20]. Y.S. Kim, Curr. Appl. Phys. 10, 10 (2010).

[21]. E. Llobet, Sens. Actuator. B-Chem. 179, 32 (2013).

[22]. B. Zhang, R.W. Fu, M.Q. Zhang, X.M. Dong, P.L. Lan, J.S.

Qiu, Sens. Actuator. B-Chem. 109, 323 (2005).
[23]. J.R. Li, J.R. Xu, M.Q. Zhang, M.Z. Rong, Carbon 41, 2353 (2003).

[24]. M. Castro-Martínez, S. Hernández-López, E. ViguerasSantiago, J. Nanomater. 2015, 607896 (2015).

[25]. M. Chanda, Introduction to Polymer Science and Chemistry (CRC Press, Boca Raton, FL, 2006) 144-152.

[26]. M. Belamares, M. Blanco, W.A. Goddard, R.B. Ross, G. Caldwell, S.-H. Chou, J. Pham, P.M. Olofson, C. Thomas, J. Comput. Chem. 25, 1814 (2004).

[27]. S. Hernández-López, E. Vigueras-Santiago, M. MendozaMora, J.R. Farias-Mancilla, E.A. Zaragoza-Contreras, Int. J. Polym. Sci. 2013, 381653 (2013).

[28]. E. Vigueras-Santiago, S. Hernández-López, C. HernándezEscobar, A. Zaragoza-Contreras, J.R. Farías, Procedia Eng. 87, 184 (2014).

(C) 2018 by the authors; licensee SMCTSM, Mexico. This article is an open access article distributed under the terms and conditions of the Creative Commons Attribution license (http://creativecommons.org/licenses/by/4.0/). 